\title{
Compromisso governamental e orçamento participativo: estudo comparativo das experiências em Blumenau e Chapecó, Santa Catarina
}

\author{
Reidy Rolim de Moura \\ Fundação Universidade Regional de Blumenau (FURB)
}

\section{Compromisso governamental e orçamento participativo: estudo comparativo das experiências em Blumenau e Chapecó, Santa Catarina}

Resumo: Aborda-se neste artigo a necessidade do compromisso governamental para com experiências de orçamento participativo, a partir da comparação dos municípios: Blumenau e Chapecó, Santa Catarina. Para tanto, destaca-se a discussão da construção de espaços públicos democráticos no Brasil, para em seguida enfatizar a variável compromisso governamental, considerada importante como elemento a ser observado quando se pretende estudar e aplicar o orçamento participativo. Destacam-se também as principais diferenças no processo de desenvolvimento do OP de Blumenau e Chapecó, focando-se o olhar na referida variável e nas formas como as forças políticas respeitaram e atenderam as deliberações deste processo participativo. Como método aplicado, utilizou-se principalmente a pesquisa documental e a de campo, com utilização entrevistas semi-estruturadas. Quanto a resultados, mostra-se que em Chapecó houve um maior compromisso do governo para com o OP e chama-se a atenção de como esta variável pode potencializar o sucesso desta experiência.

Palavras-chave: orçamento participativo, esfera pública, compromisso governamental.

\section{Government Commitment and Participatory Budget: a Comparative Study of Experiences in Blumenau and Chapecó, Santa Catarina}

Abstract: This article addresses the need for government commitment to participatory budget (PB) experiences, based on a comparison of processes in two municipalities: Blumenau and Chapecó, Santa Catarina. The discussion about the construction of democratic public spaces in Brazil is reviewed and the factor of government commitment is then emphasized. This is considered an important element to be observed in studying and applying the participative budget. The principal differences in the process of developing the PB in Blumenau and Chapecó, were analyzed, focusing on this variable and on the ways that political forces respect and attend the deliberations of this participatory process. The study principally used document and field research as well as semi-structured interviews. The results show that in Chapecó there was greater government commitment to the PB, which made clear how this can improve the chances for success of this experience.

Key words: participative budget, public sphere, government commitment. 


\section{Introdução}

Nesta pesquisa problematiza-se a priori a questão da construção de espaços públicos no Brasil, utilizando-se das referências de 'esfera pública' na noção habermasiana, no intuito de adentrar no que vem sendo ressaltado como importante quando se fala em condições de exercício da democracia em espaços já existentes, tais como: orçamentos participativos, conselhos gestores, fóruns, congressos. Discute-se sobre o 'compromisso governamental' nas experiências de orçamento participativo (OP), trazendo o seu significado e sua importância, para em seguida apresentar e discutir os dados da configuração desta variável em Blumenau e Chapecó, municípios de médio porte do estado de Santa Catarina.

\section{Metodologia}

Os elementos que resultaram nesta discussão, foram obtidos a partir de uma pesquisa empírica ${ }^{1}$, na qual se utilizou um conjunto de procedimentos de coleta de dados: entrevistas qualitativas, baseadas em roteiro estruturado com agentes sociais participantes do OP nas duas cidades integrantes da equipe de governo e da equipe do OP nos municípios (a escolha da amostra foi intencional); pesquisa em jornais locais; pesquisa documental (documentos referentes aos processos de OP municipais, à trajetória política e asso-ciativa dos dois municípios, cartilhas e folders explica-tivos); participação e observação de eventos do OP; surveys já realizados sobre os OPs municipais com consultas aos dados coletados e sistematizados no período de 1998 à 2001, resultantes de pesquisas de iniciação cientifica; e consulta a pesquisas já realizadas de interesse ao trabalho - relatórios de pesquisas, monografias, dissertações e outras obras sobre as características histórico-políticas e associativas nos municípios, cujos dados foram utilizados como fontes secundárias. Em relação ao tratamento dos dados, foram realizados relatórios para posterior análise e cruzamento, a fim de buscar esclarecer as divergências e afinidades entre as informações provenientes das diversas fontes de pesquisa.

\section{A noção de esfera pública no aprofundamento da democracia}

Conforme o Grupo de Estudos para a Construção Democrática $^{2}$ (GECD, 1999, p. 44), na medida em que "a mudança de espaços públicos torna os mecanismos de decisão política permeáveis à influencia dos setores da sociedade civil, que geralmente têm sido mantidos à margem desses processos," haverá questionamento tanto das ações do Estado como dos interesses da sociedade civil, gerando, assim, uma ampliação da política. Um outro fator de relevância da ampliação da esfera pública no âmbito do aprofundamento democrático é a contribuição para um aprendizado e consolidação de uma cultura de direitos, na medida em que a participação nos espaços públicos "possibilita a convivência entre interlocutores portadores de interesses diferenciados reconhecidos como legítimos" (GECD, 1999, p 44).

Há ainda o fato de que o espaço público, tendo como fundamento o "reconhecimento do outro como um sujeito portador de direitos, tenta burlar as assimetrias de poder e oferecer um campo regulado democraticamente para a administração dos conflitos" (GECD, 1999, p. 44). Dessa forma, viver experiências de constituição de espaço público, como no caso do orçamento participativo, pode favorecer a ampliação e o aprofundamento da democracia, bem como levar a ação da política a visar o bem comum.

O papel da esfera pública tem sido objeto de discussão para diferentes correntes teóricas, destacando-se na contemporaneidade as abordagens de Habermas (1984, 1997) Arato e Cohen (1994), que em trabalhos recentes têm discutido a redescoberta da sociedade civil e sugerido um terceiro modelo de democracia, baseado no modelo discursivo. É justamente no debate dos direitos e no caminho de afirmação da cidadania que surge a importância da constituição da esfera pública para a democratização da sociedade. A esfera pública ocupa uma posição importante no processo de decisões políticas, pois é nela que acontece a aglutinação da vontade coletiva e a justificação de decisões políticas acertadas previamente (COSTA, 1994, 1997).

Na obra A transformação estrutural da esfera pública, Habermas (1984) coloca que o processo histórico que levou à ascensão da burguesia permitiu o estabelecimento de uma nova relação com o poder político, onde o público emerge como o resultado de 
um processo no qual os indivíduos cobram dos governantes transparência nas suas decisões e justificação moral dos seus atos.

A esfera pública, de acordo com Habermas, está relacionada com a idéia de espaço de integração dos indivíduos face a face, para debater decisões tomadas pelas autoridades políticas, conteúdos morais das relações existentes na sociedade e apresentando demandas em relação ao Estado. Como analisa Avritzer (1999, p. 30-31), "o conceito de publicidade incorpora no interior da teoria democrática a inspiração participativa republicana sem, no entanto, transformá-la em uma forma alternativa de administração pública." E ainda "os indivíduos no interior de uma esfera pública democrática discutem e deliberam sobre questões políticas, adotam estratégias para tornar a autoridade política sensível às suas discussões e deliberações."

Sendo assim, o conceito de publicidade ganha uma dinâmica no interior da política, que não é movida nem por interesses particulares, nem pela concentração de poder com o objetivo de tentar dominar outros indivíduos. Contrariamente, a idéia é de que o uso público da razão estabelece uma relação entre participação e argumentação pública. Em segundo lugar, a esfera pública no conceito habermasiano contém a idéia da abertura para discussões públicas de diversas questões - como a dominação sobre a mulher, a exploração da mão-de-obra nas fábricas - que geralmente eram relegadas à esfera privada. Essas questões passam a fazer parte da discussão pública, tornando-se passíveis de argumentação racional (HABERMAS, 1984). Este conceito de público remete a uma dimensão histórica e sociológica que acompanhou a realidade das transformações do Estado moderno, ou seja, a uma esfera pública como terceira arena societária, localizada entre a sociedade civil e a autoridade do Estado, em vista das mudanças transformações estruturais, políticas e culturais que surgiram (HABERMAS, 1984).

$\mathrm{Na}$ análise de Avritzer (1999), o conceito que Habermas traz de esfera pública rompe com dois elementos da tradição elitista democrática. O primeiro elemento é caracterizado pela idéia da impossibilidade de existir formas de administrações participativas. Aqui Habermas inclui um nível adicional para a participação política ao distinguir Estado e esfera pública. $\mathrm{O}$ segundo, diz respeito à diferenciação entre $\mathrm{o}$ problema do bem comum e as formas de alcançá-lo, onde "o bem comum pode ser formal e ser pensado em termos da capacidade dos diferentes atores sociais para publicizar sua luta contra formas privadas de dominação" (AVRITZER, 1999, p. 32). Sendo assim, a esfera pública tem efeito de repercussão, que pontua o que deve ser processado pelo sistema político, cujo núcleo, segundo Habermas (1997), é formado pelos complexos institucionais administrati- vos, pelo Judiciário e pela formação da opinião e da vontade, ou seja, pelas partes parlamentares, eleições e pela concorrência entre partidos.

O poder de ação do sistema político varia, de acordo com Habermas (1997), conforme a densidade e complexidade de sua organização, estando mais ou menos aberto à formulação de respostas sob a forma de políticas ou de legislações. As demandas precisam atravessar o que o autor denomina de comportas que são ligadas estruturalmente às forças que compõem o sistema político. Dessa forma, a esfera pública pode ser vista como aquela estrutura intermediária entre o sistema político e os setores do mundo da vida. Este último corresponde ao conjunto de tradições e conteúdos compartilhados por um grupo social, bem como inclui os processos de socialização e interação que formam os sujeitos, abrangendo a intimidade, as vivências pessoais nas relações de parentescos e de amizade.

Silva (2000), ao fazer um debate sobre conselhos municipais, considera necessário que as questões surgidas no mundo da vida, para ocuparem lugar na agenda pública e tornarem-se visíveis perante o sistema político, sejam tematizadas nos meios de comunicação de massa, e recebam apoio através de campanhas, manifestações, protestos, ou qualquer forma de pressão, com o intuito de formar opinião pública.

Ainda segundo Habermas (1997, p. 94), estas questões do mundo da vida, devem ser consideradas pelo amplo debate e mobilização, que implica em informação e construção de argumentos e, sobretudo, na liberdade de reunião e de criação de associações representativas de interesses de grupos específicos.

Na esfera pública é que se dá o confronto de opiniões, de modo a atingir os espaços de tomada de decisão no âmbito do sistema político, isto é, a opinião pública representa um potencial de influência nesse sistema. Neste sentido, quem acaba por absorver e reconhecer os problemas que emergem do mundo da vida e são transportados para o sistema político é a sociedade civil. Para Habermas (apud SILVA, 2000), são as organizações e os movimentos que apreendem os problemas sociais, os quais repercutem nas esferas privadas, condensam-se e são transmitidos à esfera pública. Ainda, segundo Silva (2000), os problemas surgem a partir do momento em que algumas demandas não são incluídas na esfera pública, sendo tratadas pela coerção e repressão, ou pela filantropia.

De acordo com Lüchmann (2002, p. 44), a esfera pública aqui parece estar pautada no estabelecimento e centralidade de uma arena de negociação e debate de interesses, sugerindo o reconhecimento do outro como sujeito de direitos, buscando canalizar os conflitos que são criados e recriados na sociedade atual para os espaços públicos. Esta teria um caráter dialógico, reflexivo, participativo e tensionador que possibilitaria uma mudança na natureza dos proces- 
sos de decisões, tornando espaços tradicionalmente fechados em espaços abertos e potencializados pela participação social.

As experiências de orçamento participativo, conselhos gestores e os fóruns Agendas 21, Estatuto da Cidade, Congresso da Cidade, são de grande importância para uma nova relação entre sociedade e Estado, bem como para uma nova forma de exercer a democracia, pois os espaços criados por estas experiências requerem uma ação social ativa por parte dos atores (individuais ou coletivos) reconhecendoos como iguais na produção das regras e das normas de procedimentos e deliberação. Sem desconhecer os limites destas experiências locais, parte-se aqui do pressuposto de que esta prática precisa conter um projeto maior que envolva o país dentro de uma nova concepção de mundo. E embora a complexidade e as desigualdades sociais sejam barreiras inevitáveis, importa enfatizar que na prática desenvolvida por estas várias experiências surgem ações e relações que vão contra a histórica tradição patronal, clientelista, excludente e limitadora do sistema político brasileiro.

\section{O compromisso governamental como variável importante no desenvolvimento do OP}

Várias denominações são usadas na literatura recente sobre o OP para tratar esta variável: vontade política, compromisso político, vontade administrativa. Porém, todas remetem para o fato de que é o compromisso governamental o grande apoio que proporciona o sucesso para os programas participativodemocráticos. Ou seja, esta variável torna-se importante na medida em que os agentes políticos governamentais conseguem reunir ações que possibilitem condições efetivas de participação popular.

Silva (2001, p. 59), em sua tese de doutorado, ao analisar as relações entre governo municipal e o OP de Porto Alegre, coloca um aspecto determinante da participação popular, a "existência de um comprometimento efetivo das forças políticas ocupantes do governo em respeitar e atender as deliberações re-

sultantes dos processos participativos." Segundo o autor, a efetivação do sistema de participação na gestão pública, além de compromisso político, depende ainda da competência governamental de criar condições que viabilizem estes processos. Nessas condições, incluem-se capacidades materiais e financei- ras que permitam concretizar as deliberações da participação, bem como espaços e processos de participação ajustados à realidade local, com formas, regras e critérios institucionais que rompam com os tradicionais obstáculos. Nessa perspectiva, os governos, através de seus discursos e práticas, podem colocar-se tanto como estimuladores e potencializadores, como podem criar obstáculos. Os agentes governamentais podem dispor dos meios de comunicação estruturas da máquina pública como as escolas e os locais de saúde - e, com a autoridade e os recursos que acumulam, têm a possibilidade de atuarem como elementos fundamentais no processo de construção da participação, se estiverem comprometidos com este objetivo. Ao contrário, podem criar impedimentos, o que irá depender de sua orientação política.

Wampler (2003) contribui nesta discussão na medida em que enfatiza que o apoio que a administração proporciona para o OP é parte integral para o seu sucesso. A administração tem que se dispor a reformar o processo de reivindicação de demandas dos cidadãos, ao qual estão acostumados, e dos representantes eleitos pela comunidade, na forma em que apresentam suas demandas ao sistema político. Ou seja, os governos têm de estar dispostos a reformar as relações políticas existentes e incluir os cidadãos no processo de tomada de decisão.

Uma das principais preocupações na variável compromisso governamental diz respeito ao OP ser ou não prioridade principal do governo. Reportando-se a Lüchmann (2002, p. 122), percebe-se que o fator central para uma gestão pública participativa não se refere somente à "sua inserção como prioridade no conjunto das propostas e objetivos políticos partidários", mas também com "o comprometimento do governo com a efetivação desta proposta." A autora reitera em sua tese a importância do projeto político-partidário, como elemento fundamental para a implementação, continuidade e aperfeiçoamento da experiência.

Em que pese às dificuldades para o estabelecimento dos limites ou fronteiras entre o compromisso e controle do governo sobre o processo, estudos apontam os efeitos negativos quando acontece o descomprometimento do prefeito e da equipe. A falta de compromisso é traduzida pela ausência nos espaços de discussão, manipulação de recursos, não realização de obras no OP, bem como pelas divergências internas no governo sobre o OP, o que resulta no desgaste e na perda de credibilidade do processo. Concorda-se com 
Lüchmann (2002, p. 133) ao considerar que a ativação de canais de participação e discussão, a presença de lideranças políticas e da equipe governamental nos espaços de discussão do OP, o respeito às decisões tomadas nos espaços públicos quanto à alocação de recursos constituem "um conjunto de atividades e estratégias que contribuem para valorização da experiência, e, por conseguinte, para um maior grau de adesão e credibilidade ao processo." O resultado disso aparecerá no aumento de locais dispostos a implementar esta experiência, tendo em vista maior confiança da população, assim como maior atendimento de demandas e participação no processo de gestão pública.

Afirma-se, portanto, a importância do compromisso governamental para com processos democrático, como é o caso do OP, a fim de garantir seu melhor desenvolvimento. Sem esquecer, porém, que o compromisso governamental deve sempre estar associado a outros aspectos para que se efetivem os objetivos previstos para o OP, como o caso das outras variáveis ${ }^{3}$.

\section{Resultados e discussões: as configurações do compromisso governamental no processo do OP em Blumenau e Chapecó}

As experiências de orçamento participativo em Blumenau e Chapecó - embora haja algumas similaridades entre os dois modelos ${ }^{4}$, o que não será possível contemplar aqui - apresentam, cada qual a seu modo, diferenças significativas quanto a variável compromisso governamental, que impactaram de maneira decisiva os seus resultados.

O processo do OP em Blumenau, apesar de ter sido a principal bandeira da coligação do governo popular nas eleições de 1997, apresentou-se marcado por tensões e conflitos. Ao contrário de uma adesão automática e natural ao processo, em diversas situações observou-se que não só não ocorreu uma articulação entre o OP e a atuação de membros do governo e vereadores da coligação liderada pelo PT, como estes acabaram entrando em choque com a dinâmica e as deliberações do OP. Esta situação ficou comprovada pelo coordenador do OP, que assumiu o cargo em novembro de 2001. Ao ser entrevistado em 2003 sobre a experiência de Blumenau, enfatizou que, quando assumiu o cargo, fazia-se necessário um aperfeiçoamento do programa, pois tinham sido detectadas algumas falhas que comprometiam até mesmo a continuidade do processo. Entre essas falhas, citou o fato do OP ser um programa de governo, e não uma secretaria, e que não tinha locação orçamentária e não executava, apenas fazia as discussões na base e trazia as prioridades.

Um dos principais problemas do OP em Blumenau foi a divergência enfrentada pelas Secretarias Muni- cipais. Durante a coleta de dados para a pesquisa, a partir das entrevistas realizadas, ficou perceptível que no governo, do período de 1997 a 2001, o OP foi muito prejudicado. Muitos agentes políticos não entendiam o seu significado e não assumiam o compromisso conforme deveriam, principalmente quando não pertenciam ao do Partido dos Trabalhadores ${ }^{5}$. A situação de conflito em algumas Secretarias Municipais também pode ser observada diretamente nas atividades anuais do OP. Em algumas rodadas e reuniões, nas quais os secretários deveriam prestar contas da atuação de suas secretarias, ou então esclarecer dúvidas para os participantes do OP, estes, mesmo quando convidados, não compareciam. Havia muita resistência por parte dos secretários em comparecer às reuniões, enviando algumas vezes um subordinado para dar as explicações solicitadas pelos membros do CMOP. Quando isto não convencia, as reuniões eram transferidas, e por tantas vezes, que os interessados acabavam desistindo (ANDRADE; MOURA, 2000). Além do não comparecimento do representante, algumas secretarias demonstravam dificuldade em aceitar as propostas do OP, revelando assim um caráter de concorrência entre elas e o OP. Estes fatos indicam a um alto grau de desvinculação do governo em relação ao OP, atentando gravemente contra a credibilidade do processo. Esta situação de conflito é mencionada por uma ex-integrante do OP - participante da implementação do processo em Blumenau, tema em que baseou sua monografia de especialização - quando afirma que desde o início "não houve entrosamento e discussão entre o Conselho Municipal do Orçamento Participativo e os outros Conselhos Municipais, muitos dos quais com o caráter sobre políticas específicas" (SILVA, 1999, p. 47).

Fato marcante também foi a rara presença do prefeito e vice-prefeito nas atividades do OP, sendo que a presença era notável em situações como as sessões de solenidade de entrega de certificado aos conselheiros e delegados, em assembléias populares quando da implementação do processo (1997-98) e também nas atividades do OP em 1999 - ano que antecedeu a reeleição do então governo. Era comum, na fala do coordenador do OP, a falta de priorização e investimento no programa, tanto de esforços políticos como financeiros, por parte do governo, sendo um dos motivos que acarretou problemas no desenvolvimento do processo em Blumenau.

A credibilidade do processo também é fragilizada ao analisarmos outro indicador da variável compromisso governamental e que pode ser traduzida pelos problemas no atendimento das deliberações de serviços e obras através do OP. Um problema bastante significativo refere-se a uma superestimativa das receitas do governo no início do OP (1997), que geraram definições de obras incapazes de ser reali- 
zadas. Em função disso, uma série de demandas incorporadas no Plano de Investimentos de 1998 acabaram não sendo executadas, gerando dúvidas sobre a credibilidade do processo e o afastamento de diversos participantes. As obras teriam sido orçadas com valores abaixo do custo, principalmente por falta de experiência de técnicos, da equipe do OP e da própria população. Outro fator importante é o percentual de investimento destinado ao OP ao longo dos 7 anos do processo, conforme expresso no quadro 1.
Partido da Frente Liberal (PFL) assumiu o Poder Executivo e o programa deixou de existir em Blumenau.

Os limites no processo do OP de Blumenau não significam que não tenha havido avanços em setores diferenciados, tanto da sociedade civil como por parte do executivo. Um exemplo foi o confronto com a Câmara de Vereadores, onde os membros tiveram que rever o seu papel frente à comunidade, principalmente quanto a atos clientelistas, já que a população começou a participar e a entender melhor sobre o processo de gestão pública.

\section{Quadro 1 - Capacidade de Investimento no OP em Blumenau}

\begin{tabular}{c|c|c}
\hline Ano & Percentual de investimento & Valor em R\$ \\
\hline 1996 & $*$ & $*$ \\
1997 & $7 \%$ & $11.000 .000,00$ \\
1998 & $3 \%$ & $4.700 .000,00$ \\
1999 & $* *$ & $* *$ \\
2000 & $1 \%$ & $5.000 .000,00$ \\
2001 & $* *$ & $* *$ \\
2002 & $* *$ & $* *$ \\
\hline
\end{tabular}

Fonte: Superintendência do OP de Blumenau.

* Dados não fornecidos.

** Não houve elaboração de um novo Plano de Investimento.

Analisando o quadro 1 no ano de 1999 não houve a elaboração de um novo Plano de Investimento, sendo que foi apresentado a Câmara de Vereadores o mesmo orçamento do ano anterior, com ênfase nas obras ainda não realizadas. Nos anos de 2001 e 2002, aconteceu a mesma situação. Ao ser indagado sobre a porcentagem geral de obras que já haviam sido concluídas desde 1997, o coordenador do OP, em agosto de 2003, afirmou que este percentual era de $68 \%$ até o momento. Conclui-se que muitas prioridades elencadas pela população na implementação do processo do $\mathrm{OP}$, não foram atendidas, o que gerava uma ansiedade e desconfiança da população quanto à sua legitimidade. Observa-se ainda que, no caso de Blumenau, a capacidade de investimento diminuiu substantivamente para as obras escolhidas pela população.

Apesar das dificuldades observadas em Blumenau, na relação governo e OP, identificou-se, desde o início, uma atuação, por parte da superintendência do OP (e de toda a equipe integrante), orientada para a mobilização e participação da população no processo, traduzida em investimentos materiais, como disponibilização de transporte, publicação de dados, produção de material informativo, como cartilhas e folders com recursos municipais. Em 2003, uma série de mudanças desenhou-se na metodologia do OP, porém, em 2004 uma outra coligação, tendo a frente o
Os fatos apresentados levam a sugerir que o OP em Blumenau não foi incorporado e assumido como uma política conjunta do governo e das forças políticas a ele associadas. Em Blumenau, parece haver um descompasso entre a idéia do OP e a adesão efetiva a esta política como orientadora das iniciativas de governo. Da mesma forma, observa-se também uma disputa e conflituosidade entre os vereadores e o OP, especialmente na definição do canal mais eficaz, dentre os de acesso às decisões governamentais, para encaminhamento das demandas da população. A falta de compromisso com o OP reflete-se também nos investimentos de recursos financeiros, o que dá margem para o descrédito e a fragilização do processo frente à população. Muitas das dificuldades internas em viabilizar o OP de Blumenau, podem estar ligadas a uma orientação restrita aos membros da equipe do OP, o que os sobrecarregava de tarefas, e os responsabilizava pela condução do processo e por responder aos anseios da população envolvida com a experiência. Entretanto, mesmo diante das limitações observadas no OP de Blumenau quanto a variável compromisso governamental, identifica-se, tendo em vista às demandas que de fato foram atendidas no município, alguma sustentação em termos das possibilidades de ampliação e fortalecimento de sua credibilidade para um futuro, tendo em vista a 
histórica experiência de exclusão de serviços públicos ao longo de governos anteriores.

Quanto ao compromisso governamental em Chapecó, pôde-se observar, a partir das informações coletadas na pesquisa de campo, uma relativa unidade do governo em termos de comprometimento e envolvimento com o processo do OP. Verificou-se que houve, diferentemente de Blumenau, a participação das Secretarias Municipais nas atividades do OP, bem como uma integração entre estas e o setor do OP para atendimento das demandas populares. Conforme as informações procedentes do setor, isso aconteceu porque, a partir da eleição das grandes áreas prioritárias do município para investimento justamente aquelas que mais iriam ser debatidas durante as rodadas do processo - a respectiva secretaria teria direito a um assento no conselho do OP.

$\mathrm{Na}$ articulação da atuação governamental e dos representantes do OP, destacou-se nas falas dos entrevistados da pesquisa, a postura do prefeito quanto à sua presença aos eventos do OP, inclusive convocando os representantes das secretarias para igualmente comparecerem. As falas deixavam transparecer que também havia conflitos na relação entre governo e $\mathrm{OP}$, entretanto, não deixaram de ressaltar inúmeras vezes o papel do prefeito quanto à importância por ele atribuída ao processo, através da atitude de decretar como obrigatória a presença dos secretários e membros do governo no OP. É nessa situação que a variável compromisso governamental mais se diferencia da situação de Blumenau, na medida em que em Blumenau não se identificou uma priorização do prefeito para com o processo, além de tensões entre o OP e outras instâncias do governo, como as Secretarias Municipais.

Já no que diz respeito à relação entre vereadores e o OP, a situação de Chapecó não se diferencia muito da de Blumenau. Também em Chapecó o OP encontrava resistências e questionamentos quanto ao papel do vereador frente ao processo. De acordo com o coordenador do OP em Chapecó, contava-se com a participação dos vereadores do campo de esquerda no OP, enquanto os vereadores de oposição ao governo provocavam constantes discussões negando a legitimidade do processo. Foi a partir dessa relação conflituosa que o OP mais contribuiu para instituir um conjunto de questionamentos sobre as relações políticas institucionais, chamando a atenção para a definição do legítimo papel do vereador.

Outro evento importante em Chapecó foi a de prestação de contas de tudo o que o governo deixou ou não de realizar nas comunidades e regiões do OP. Nos primeiros anos de OP, essa prestação de contas realizava-se nas diferentes regiões da cidade. Eram apresentados vídeos, peças de teatro, e a população podia participar para fazer perguntas e questionamentos. Essa dinâmica de prestação de contas começou a se aperfeiçoar na medida da ne- cessidade, como por exemplo, quando as assembléias começaram a esvaziar.

A equipe do OP de Chapecó colocou, durante as entrevistas que era necessário o próprio governo ingressar no processo para também disputar recursos orçamentários. Com isso ficou claro que, apesar da necessidade de certas obras para o município, a sua realização não se definia no gabinete. Ao contrário, o governo discutia o OP com a população em assembléia regional. A partir do debate, do convencimento, da amostra de dados, de números, percentuais e diagnósticos, apresentava a situação à população, para manifestar que as decisões não seriam tomadas de forma unilateral. Com essas atitudes, que demonstram maturidade política, o governo de Chapecó estaria construindo um orçamento viável, utilizando-se do debate e do consenso, com a participação de todos os atores sociais do município. Entretanto, ao mesmo tempo que este fato pode ser analisado como positivo, pode ser questionado. Como se desenvolvia esta negociação de demandas do poder público e da comunidade, tendo em vista alguns fatores que podem desfavorecer a população no debate, tais como: o domínio e o saber técnicos, o discurso, a capacidade de argumentação?

A atuação do governo em relação ao OP não se resumia somente a um compromisso com o processo em si. O governo desempenhou papel importante também ao priorizar a execução das obras escolhidas pela população. Segundo o coordenador do OP, ao ser indagado sobre a situação das obras escolhidas em 2003, ele coloca que $90 \%$ das obras apresentadas pela comunidade durante as reuniões do $\mathrm{OP}$ em 2002 já haviam sido concluídas e as 10\% restantes seriam concluídas até a metade daquele ano, uma vez que já estavam em andamento. Esse fato indica a capacidade do governo de responder à expectativa e às demandas geradas, causando bom impacto para a credibilidade da experiência em Chapecó.

Importante também era a preocupação da equipe do OP em conjunto com todo o governo na superação de obstáculos, na execução de obras. Nesse sentido, destacam-se as medidas financeiras adotadas em Chapecó para aumentar a capacidade de investimento do município. A situação financeira da prefeitura, conforme consta na prestação de contas do município, desde 1996, melhorou significativamente. Um dos motivos foi o aumento no número de contribuintes em dia com o IPTU: de 44\% em 1996, passou a 72\% em 1999. Isso possibilitou a ampliação dos serviços públicos e realização das obras definidas pela população no OP. Houve ainda o aumento da arrecadação com a cobrança de grandes devedores. O incentivo foi um prêmio para quem estivesse em dia com as prestações: um desconto de $10 \%$, lançado no carnê de 2000. Medidas como essa colaboraram com o aumento do percentual para investimento no OP no decorrer dos anos de sua vigência, o que se pode conferir no quadro 2 . 


\section{Quadro 2 - Capacidade de investimento no OP em Chapecó 1996-2002}

\begin{tabular}{c|c|c}
\hline Ano & Percentual de investimento & Valor em R\$ \\
\hline 1996 & $4,7 \%$ & $1.658 .678,06$ \\
1997 & $10 \%$ & $3.732 .689,80$ \\
1998 & $10,64 \%$ & $4.752 .823,62$ \\
1999 & $10 \%$ & $5.150 .328,40$ \\
2000 & $*$ & $*$ \\
\hline
\end{tabular}

Fonte: Departamento do OP de Chapecó

* Informação não obtida.

Consta na cartilha de prestação de contas de 2000 que, em 1996, os recursos próprios para investimentos em Chapecó eram de 1.658.678,06 reais $(4,7 \%)$. Em 1997, este valor aumentou para $3.732 .689,80$ reais $(10 \%)$. Em 1998, foram investidos $4.752 .823,62$ reais $(10,64 \%)$ e, em 1999, o valor para investimentos foi para $5.150 .328,40$ reais $(10 \%)$. (CHAPECÓ, 2006). Os investimentos no ano de 2002, de acordo com as informações repassadas pela equipe da prefeitura, foram de, aproximadamente, 9,5 milhões, apresentando aumento nas obras do OP em relação aos anos anteriores, aplicados nos segmentos apontados pelas comunidades. Constata-se que a capacidade de investimento em Chapecó diferenciou-se muito da de Blumenau, onde se verificou uma diminuição dos recursos para o OP. A execução das obras no OP de Chapecó só veio a contribuir para a potencialização, legitimidade e $\mathrm{o}$ aumento da credibilidade no processo por parte da população.

Percebe-se assim que em Chapecó o comprometimento do governo para com o OP parece fator central em termos de mobilização para participação, condições efetivas de cumprimento dos planos de investimentos discutidos pela população e respeito aos princípios educativos que a experiência engendra. Percebe-se que há um compromisso com a proposta do OP no município, bem como esforços para uma gestão com transparência e com a intenção de mobilizar a participação da população em programas e projetos instituídos pelo poder público. Isso é perceptível devido à prestação de contas e à divulgação do OP, além de outras políticas e outros programas adotados pelo governo.

Não é nossa intenção apresentar Chapecó como uma ilha isenta de relações conflitantes ou clientelistas, que, como sabemos, permeiam historicamente as relações entre governo e sociedade no espaço público brasileiro. Mesmo porque houve dificuldades na implementação destes programas participativos e descentralizados, e há uma tradição de relações de favor e troca na região, que ainda precisam ser superadas. No entanto, não podemos deixar de destacar, que havia uma intenção da administração municipal de Chapecó de alterar as relações historicamente patro- nais e clientelistas, construindo cidadãos mais críticos e envolvidos com a coisa pública. Baseados em ações que promovem a participação, a descentralização e a transparência na gestão administrativa, Chapecó vinha mostrando fragmentos de empoderamento de seus cidadãos, juntamente com um processo de accountability. Destaca-se inclusive que o OP não é a única forma de participação dessa cidade, embora se destaque no conjunto de espaços participativos como os Conselhos Locais de Saúde, os Conselhos Municipais em todas as áreas, a eleição de diretores das escolas cunicipais, Conferência Municipal de Assistência Social, educação e saúde.

\section{Considerações finais}

Buscou-se nesta pesquisa levantar elementos para verificar a eficácia da gestão do orçamento participativo nos município de Blumenau e Chapecó. Em Blumenau, o governo municipal não incorporou o processo, o que se refletiu na falta de investimentos dos recursos financeiros, na criação de tensão entre representantes locais e na fragilização e no descrétido do programa junto à população. Em Chapecó, o poder local compromissou-se com a proposta do OP, possibilitando condições efetivas para o cumprimento dos planos de investimentos discutidos pela população. Apesar do sucesso, não houve isenção de conflitos na relação governo e OP, principalmente devido à tradição de práticas clientelistas dos agentes políticos.

Espera-se que este estudo comparativo de experiências de OP contribua para o debate democrático atual - considerando a importância do programa. Há muito para se pensar quanto a alternativas em relação aos limites da democracia representativa. É preciso considerar as inovações na área de argumentação e deliberação, as experiências já realizadas, quando se pretende implementar o OP em diferentes contextos. É preciso, também, atentar para a variável aqui analisada, a fim de criar condições positivas para o desenvolvimento de futuras experiências, sem desconsiderar, con- 
forme já assinalado, as outras variáveis pertinentes de estudo, como desenho institucional e tradição associativa.

\section{Referências}

ANDRADE, E. T. De: MOURA, R. R. de. Poder local, participação popular, descentralização e clientelismo: a experiência do orçamento participativo de Blumenau. Blumenau: FURB, 2000. Relatório técnico de final de pesquisa.

ARATO, A.; COHEN, J. Civil Society and Political Theory. Cambridge: The MIT Press, 1994.

AVRITZER, L. Teoria democrática, esfera pública e participação local. Sociologias, Porto Alegre, ano 1, n. 2, jul./dez. 1999.

CHAPECÓ. Prefeitura Municipal. Orçamento participativo. Cartilha de prestação de contas - 2000. Disponível em: <http://www.chapeco.sc.gov.br/prefeitura/portal/>. Acesso em: dez. 2006.

COSTA, S. Esfera pública, redescoberta da sociedade civil e movimentos sociais no Brasil. Novos Estudos CEBRAP, São Paulo, n. 38, p. 38-52, mar. 1994.

. Contextos da construção do espaço público no Brasil. Novos Estudos CEBRAP, São Paulo, n. 47, p. 179192, mar. 1997.

GECD. Grupo de Estudos sobre a Construção Democrática. Os movimentos sociais e a construção democrática. Sociedade civil, esfera pública e gestão participativa. Idéias, IFCH, UNICAMP, Campinas, v. 5, n. 2, v. 6, n. 1, p. 7-122. (Dossiê sobre movimentos sociais).

HABERMAS, J. Mudança estrutural da esfera pública. Rio de Janeiro: Tempo Brasileiro, 1984.

. Direito e democracia: entre facticidade e validade. Tradução de Flavio Beno Sieneichler. Rio de Janeiro: Tempo Brasileiro, 1997.

LÜCHMANN, L. H. H. Possibilidades e limites da democracia deliberativa: a experiência do orçamento participativo de Porto Alegre. Campinas, 2002. Tese (Doutorado em Ciências Sociais) - Universidade Estadual de Campinas, 2002.

MOURA, R. R. de. Compromisso governamental, desenho institucional e tradição associativa: o orçamento participativo em Blumenau e Chapecó. Florianópolis, 2004. Dissertação (Mestrado em Sociologia Política) Universidade Federal de Santa Catarina, 2004.
SILVA, M. K. Construção da 'participação popular': analise comparativa de processos de participação social na discussão publica do orçamento em municípios da região metropolitana de Porto Alegre/RS. Tese (Doutorado em Ciência Política) - PPG Sociologia, Univesidade Federal do Rio Grande do Sul, Porto Alegre, 2001

SILVA, M. S. da. Conselhos Municipais dos direitos da criança e do adolescente do médio vale do Itajaí/SC. O perfil, o conteúdo e os organizadores da agenda. Florianópolis: UFSC, 2000. Dissertação (Mestrado em Sociologia Política) - Universidade Federal de Santa Catarina, Florianópolis, 2000.

SILVA, R. W. O orçamento participativo enquanto espaço de participação popular - a experiência de Blumenau no ano de 1997. Florianópolis: UFSC, 1999.

WAMPLER, B. Orçamento participativo: uma explicação para as amplas variações nos resultados. In: AVRITZER. L.; NAVARRO, Z. (Org.). A inovação democrática no Brasil: o orçamento participativo. São Paulo: Cortez, 2003.

\section{Notas}

1 Este trabalho apresenta parte dos dados obtidos para a dissertação de mestrado apresentada ao Programa de Sociologia Política da Universidade Federal de Santa Catarina (MOURA, 2004).

2 O GECD é vinculado ao Instituto de Filosofia e Ciências Humanas da Universidade de Campinas.

3 As variáveis que não são abordadas neste artigo são: desenho institucional e tradição associativa. Para maiores informações acerca dessas variáveis em Blumenau e Chapecó, indicamos Moura (2004).

4 Uma caracterização dos municípios citados e o processo de implantaçãoe desenvolvimentodo OP nestes, ver Moura, 2004.

5 Alguns secretários nomeados na gestão de 1997 a 2000 e a 2001-2004 eram filiados a outros partidos, como por exemplo o PMDB, o que gerava alguns conflitos nos encaminhamentos das obras no município na época.

\section{Reidy Rolim de Moura}

Assistente Social

Doutoranda no Programa de Sociologia Política na

Univ. Federal de Santa Catarina (UFSC)

Professora Substituta do Dep. de Serviço Social da FURB

Rua Antônio da Veiga, 140 - Victor Konder,

Blumenau - Santa Catarina.

CEP: 89012-900 